\title{
Erratum to: Understanding the relationship between teachers' pedagogical beliefs and technology use in education: a systematic review of qualitative evidence
}

\author{
Jo Tondeur ${ }^{1,2} \cdot$ Johan van Braak ${ }^{1}$ Peggy A. Ertmer ${ }^{3}$. \\ Anne Ottenbreit-Leftwich ${ }^{4}$
}

Published online: 27 September 2016

(c) Association for Educational Communications and Technology 2016

\section{Erratum to: Education Tech Research Dev DOI 10.1007/s11423-016-9481-2}

Two wrong affiliations were attributed to the first and third authors: Jo Tondeur is not affiliated with the Department of Curriculum and Instruction, College of Education, Purdue University,West Lafayette, IN, USA; Peggy A. Ertmer is not affiliated with the Interfaculty Department for Teacher Education, Vrije Universiteit Brussel, Brussels, Belgium.

The online version of the original article can be found under doi:10.1007/s11423-016-9481-2.

Jo Tondeur

Jo.Tondeur@UGent.be

1 Department of Educational Studies, Ghent University, Henri Dunantlaan 2, B9000 Ghent, Belgium

2 Interfaculty Department for Teacher Education, Vrije Universiteit Brussel, Brussels, Belgium

3 Department of Curriculum and Instruction, College of Education, Purdue University, West Lafayette, IN, USA

4 Instructional Systems Technology, School of Education, Indiana University, Bloomington, IN, USA 